\title{
Organic and Cultural Evolution can be Seamlessly Integrated Using the Principles of Communication and Problem-Solving: The Foundations for an Extended Evolutionary Synthesis (EES) as Outlined in the Mega-Evolution Concept ${ }^{1}$
}

\begin{abstract}
Arnold De Loof ${ }^{2}$
Abstract: When the "sender-receiver", also known as "communicating compartment", instead of "the cell", is adopted as the universal unit of structure and function of living matter, organic- and cultural evolution automatically emerge as the two sides of the same coin. This proposed conceptual switch makes "problem-solving activity" instead of gene-protein activity a key in understanding adaptation and evolution. The concept "problem-solving activity" has no teleological meaning in neo-Darwinism. This paradigm shift also allows for a plausible definition of "life" (L), as the sum of communication acts $(\mathrm{C}), \mathrm{L}=\sum \mathrm{C}$. Any sender-receiver harbors two memory systems: genetic and cognitive. Using a human metaphor, where relevant, two types of progeny can (co)exist: "physical children" and "pupils". Any act of communication is a problem-solving act, because all messages, regardless of their nature, are coded. Hence, any receiver invariably faces the problem of how to extract and respond to the incoming information. Some biological problems are solved "the hardware way" (Darwinian organic evolution), others "the software way" (Lamarckian cultural evolution). Mega-Evolution means life's evolution as a hardware-software double continuum governed by the principles of both genetics and communication.
\end{abstract}

Key Words: cognitive memory, communication, definition of death, definition of life, Extended Evolutionary Synthesis (EES), Intelligent Design, Mega-evolution, meme, Neo-Darwinism, organicand cultural evolution, problem solving, selfish gene, unit of selection

\section{Introduction}

Since the Last Universal Common Ancestor (LUCA) came into being over 3 billion years ago, it evolved into numerous species that are all linked genetically by the principle of common descent. Although genetic drift, migration, assortative mating and selection are responsible for genetic variability, new alleles are ultimately formed through mutations (Kauffman 1993). This represents the very heart of the Modern Synthesis of Evolutionary Theory, the merger of genetics with Darwinism (Neo-Darwinism), which occurred during the first half of the $20^{\text {th }}$ century. Although the view that "the genotype of each organism in a population plays a dual role as both the motor of individual development and as the sole causal channel across the generations" is known to be too restrictive, even false (Sterelny 2000), it persists unabated. Yet, unconditional support for this view is fading, be it reluctantly (Laland et al. 2014).

\footnotetext{
${ }^{1}$ Received on November 20, 2014.Accepted on December 30, 2014. Last revisions received on January 8, 2015.

${ }^{2}$ Functional Genomics and Proteomics Group, Department of Biology, KU Leuven-University of Leuven, Belgium. E-mail: arnold.deloof@bio.kuleuven.be
}

DOI: 10.9784/LEB2(4)DeLoof.01

Electronically available on January 10, 2015. Mailed on January 10, 2015 
In this context, a major point of discussion is: from which principle(s) should one start formulating an Extended Evolutionary Synthesis (EES) in which classical organic evolution and cultural evolution emerge as two faces of the same coin? Remarkably, although it is self-evident that any EES should be the umbrella above micro- and macroevolution as well as deal with the evolution of "life", the implication that agreeing upon a plausible definition of "life", an absolute prerequisite before engaging in formulating any novel EES, is seldom or not at all acknowledged.

According to the principle of common descent in evolutionary theory, all organisms on Earth are genetically related. Evidently, after billions of years of evolution this relationship has become diluted through the possibilities of generating genetic variability. Obviously, organisms are connected to others belonging to the same or to other species by all sorts of means of interactive communication (visual, sonic, chemical, etc.) which, like genes, are also subject to evolutionary change. The transfer of information through such non-genetic channels is much faster than through the genetic channel. The transfer of information through the so-called "central dogma DNA $\rightarrow$ RNA $\rightarrow$ Proteins" (Crick 1970), which is the cornerstone of molecular genetics, takes at least minutes, even under optimal conditions. In contrast, the handling of information through the nervous (and other) system(s) as well as the cognitive memory, only takes milliseconds. This is in part due to the essential role of the electric dimension of cells in the cognitive memory system. All prokaryotic and eukaryotic cells generate their own electricity carried largely by inorganic ions. They use it for a variety of functions, including the control of gene expression (De Loof 1986). These non-Central Dogma facts have been insufficiently considered in the New Synthesis (Gould 2002). Because not all elements of the cell's electric system are integrally encoded by genes, not all transfer of information within generations and from generation to generation, etc. can be solely/fully be explained by the principles of (molecular) genetics.

In addition to gene activity, the use of means of communication, or languages of all sorts, not only human language with all its aspects, influences evolution. The enormous variability in our daily conversations as well as the phenotypic variability that results from information transmitted across generations through social learning (a definition of culture) are typical examples. Culture is the product of innovation and social learning. Yet, the importance of using a language and learning depends on the species and their way of life. Learning likely offers more advantages for free-living organisms, like many animals, than for sessile organisms, like most plants.

To date, the conceptual underpinnings of this double genes-languages continuum concept remains deficient, in particular when dealing with the evolution of free-living organisms. For example, in the "inclusive inheritance" approach that underlies the extended theory of evolution of Danchin et al. (2010, 2011), the systematic use of "heritability" for all forms of transferability of 
information across generations (genetic, epigenetic, ecological, and cultural as well as parental effects) is confusing. It suggests, probably unintentionally, that evolution boils down to changes in genes and in gene regulatory networks (Day and Bonduriansky 2011, Gould 2002, Huang 2011, Moore 2012). Even if one (rightly) disagrees, one has to accept that as long as biologists think in terms of only one type of memory, a genetic one, and consequently of one "central dogma "DNA $\rightarrow$ RNA $\rightarrow$ Proteins", an "inclusive inheritance" approach is a logical, but not necessarily the scientifically correct outcome. Below, I explain why.

A novel physiology-based integrative paradigm, on which scientists that accept evolutionary theory independent of their specific field of interest can agree, is needed. In this approach, not only genes are taken into account but also the electric dimension of cells as an instrumental portion of the cognitive memory system (Noble 2013, Danchin and Pocheville 2014). At first sight, this may look like an incredibly difficult task, but it is not if one considers that, both broad disciplines, organic and cultural evolution, ask the same questions, namely: how do organisms solve problems caused by changes in their internal and external environments, and how can problem-solving activity, which has no teleological perspective, change over time? This approach redirects the current emphasis on molecular biology and genetics towards communication. Indeed, problem solving does not follow integrally from molecular genetics. Genes are not more than recipe pages in the genomic cookbook for proteins. Hence, naked genes are unable to solve any problem on their own. Evidently, genes play an essential role, but only in the context of a higher-order principle of a different nature that states that all living matter is organized in sender-receiver - or communicating compartments. Because such compartments can handle information, they have the potential to solve problems. One should not interpret this as if problem solving has a teleological perspective; there is no goal whatsoever in evolution.

The principles of communication and problem solving are as important to biology as are those of genetics. Yet, communication and problem solving are seldom adequately explained in textbooks of classical biology. However, the counterintuitive fact that any act of communication is a problem-solving act and hence potentially causal to adaptation, makes it of primordial importance for bringing about evolutionary change as well as for better integrating the various subdisciplines of biology, in particular for upgrading the so-called New Synthesis.

\section{The principles of communication: a concise outline What is communication?}

The word "cell" is derived from the Latin, "cellula", a small room or compartment. In biology, cells are the small compartments, or chambers, that make all living things, such as those in cork. Thus, in origin, "the cell" is a 
morphological concept. The concept "sender-receiver", which is functional in nature, dates from much later in the history of biology than cell.

Numerous definitions of communication exist, indicating that it is difficult to take into account concurrently the key aspects of such complex activity. A simple, yet workable, definition for biologists follows: communication is the transfer of information that is executed in what is commonly called "a senderreceiver" or "communicating compartment". Similarly, a practical introductory definition of "information" is: "a message contains information when, upon its decoding, the receiver starts mobilizing, sooner or later, part of its stockpiled energy for engaging in some sort of "work". This definition may be somewhat too simplistic if one considers that most signals received by sense organs are filtered so that they are not stored. In my view, information is immaterial; it has no mass, but it usually requires a material carrier for its transport. Absence of something can act as information on condition that the program for interpreting presence versus absence is present in the brain. Another example, a testosterone molecule stored in a bottle does not carry information. It is only when the molecule meets a matching receptor somewhere in a cell that testosterone gets a meaning as a messenger of information. Upon binding to the receptor, testosterone itself does not loose mass. The only thing it does is to activate a signaling cascade .If one accepts that handling information is an intelligent activity, then all cells, no matter their morphology or function, are provided with "an intelligent dimension". We tend to associate "intelligence" with higher vertebrates and in particular with humans. One may become skeptical when socalled "lower organisms" are also considered "intelligent". It has been shown that bacteria can learn. Why should this learning be less intelligent than that of humans? If they can learn, they must have a cognitive memory system that is likely based upon the same universal principles as the human one. In my opinion, the difference is not so much qualitative but quantitative. In particular, advocates of Intelligent Design (c.f. NOVA 2007, Padian 2009), who tend to focus exclusively on Homo sapiens, argue that such a dimension - "a brain" - is missing in Neo-Darwinism. Hence, they regularly, but unfairly, use this argument as ammunition against Darwinism, a splendid, but admittedly still incomplete theory of evolution.

\section{The architecture of a communicating compartment}

A communicating compartment (Figure 1) invariably consists of a sender (living or non-living) that emits messages always written in coded form. Upon release, the message is unidirectionally transported through a communication channel (e.g. air, blood, axon, etc.). If the messenger matches the receptor(s) present in the receiver, a signaling cascade is triggered involving decoding, amplifying (e.g. by a huge rise in intracellular $\mathrm{Ca}^{2+}$ concentration; this rise should be temporary since a prolonged exposure will kill the cell), and mobilizing part of the stockpiled energy for doing some sort of "work" sooner or 
later, or responding. Decoding requires preexisting decoding programs (see section entitled "Two memory systems", page 257). In case of feedback, the receiver becomes a sender that formulates a new message, and the cycle continues.

Thus, communication is about the meaningful use of signs. The term "semiotics" is commonly used in the humanities (Chandler 2002, Eco 1978). Molecules, such as neurotransmitters and semiochemicals (e.g. hormones, pheromones, kairomones, neuromodulators with their widespread effects on both genes and ion channels etc.) and their receptors are the most studied elements of cellular signalling pathways.

\section{Sources of communicational variability}

From Figure 1, it can be deduced that the possible sources of communicational variability are numerous. First, the diversity of possible messages that are subject to interpretation is huge. Second, the architecture and biochemistry of the sender, its messages (nature, content, length, intonation, clicks, the frequency, as in the case of trains of action potentials, etc. Baronchelli et al. 2012), the transmission channel, the receiver, the gradients, the energy supply, the nature and storing of decoding programs, the sort of answer(s), the signaling cascades, the formation and functioning of the intermediate and long-term memory (Parvez et al. 2005, Azami et al. 2006, Rosenegger et al. 2008, 2010), the feedback and decision making, etc. are all subject to change. Reali and Griffiths (2010) compared words to alleles. Earlier, Richard Dawkins (1976) had introduced the term "meme", which stands for "an idea, behavior, or style that spreads from person to person within a culture". A meme acts as a unit for carrying cultural ideas, symbols, or practices that can be transmitted from one mind to another through writing, speech, gestures, rituals or other imitable phenomena with a mimicked theme. Supporters of the concept regard memes as cultural analogues of genes in that they self-replicate, mutate, and respond to selective pressures" (Dawkins 1989). I am not enthusiastic about this concept as it mostly applies to humans, hence it has no general value. Humans can only use memes if they have in their brain the appropriate decoding programs. They inherited them from evolutionarily ancient ancestors. What biochemical signaling cascades/processes enable the use and propagate memes? Are the decoding- and responding programs for all memes different, or are they variants from a common theme? As long as we do not know how the cognitive memory functions at the (sub)cellular level, it will remain difficult to elucidate the mechanisms involved. Therefore, I prefer to use "software programs and their evolution" 


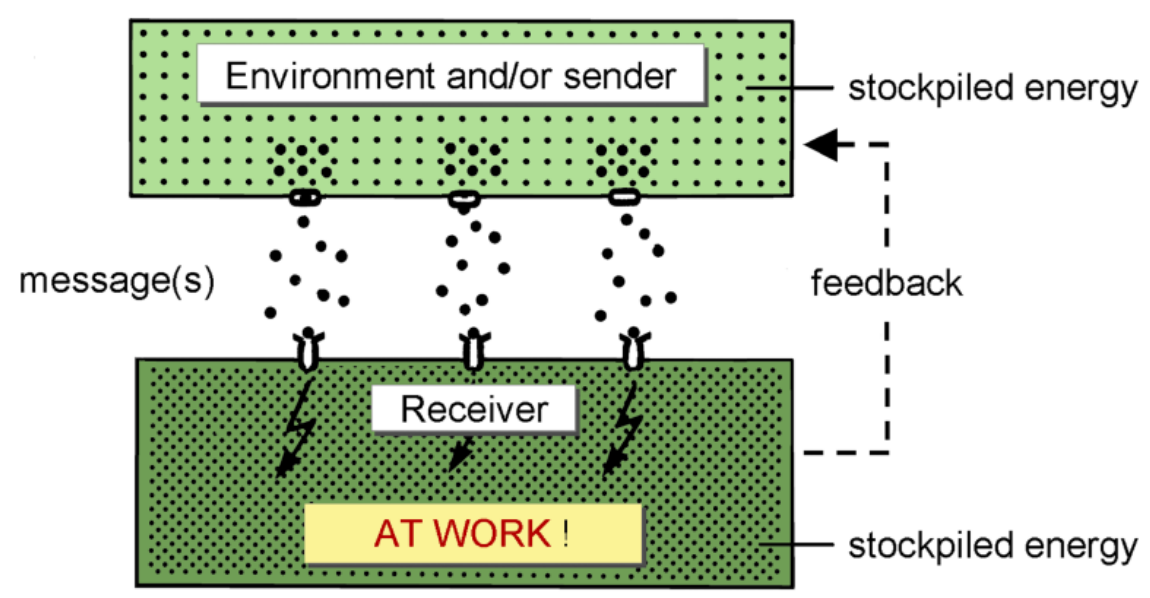

Figure 1. Schematic representation of the architecture of a simple communicating compartment and of the components of a communication act.

How to bring order in the multitude of different communicating compartments?

Introductory biology textbooks usually list several levels of complexity, such as molecules, organelles, prokaryotic and eukaryotic cells, tissues, organs, organ systems, multicellular organisms, populations, communities, and the ecosystems. How these levels are linked is seldom explained. For example, a mitochondrion is a bacterium-like organism with its own genome that lives as a symbiont in most eukaryotic cells while the endoplasmic reticulum is not more than a membranous sac without an own genome. Besides a few exceptions, such as the random inactivation of the second $\mathrm{X}$ chromosome in mammals, or, more dramatically, the phenomenon of diminution, all cells of the body of a multicellular organism have the same genome. This is no longer the case for the different individuals of a population, which are different from each other genetically. That is even more the case for communities or biocoenoces. This poses a problem for an only-genetics approach to evolution that encompasses all levels of the biological hierarchy.

There is a better alternative for bringing both order and logic to the tangle of current communicating systems. There is a system, different from the classical genetic/morphological/behavioral grouping systems, based upon the principles of communication (De Loof and Vanden Broeck 1996, De Loof 2002). It starts from the fact that the first cell on Earth, the progenote, functioned as the primordial sender-receiver compartment. Upon fission, it shared its communication abilities with the daughter cell that in its turn did the same and so on and on, in an uninterrupted way into all current organisms (Figure 2). Here rises another fundamental question: what is the reason that at some point in this uninterrupted (ontogenetic) way, daughter cells become for 
the first time fundamentally different from their parents in that they morphologically differentiate (micromere vs. macromere formation). Here sender/receiver capacities remain present, but change in nature.

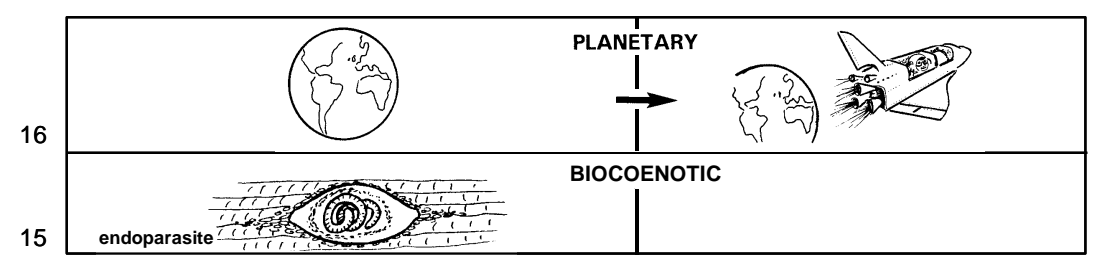

COMPARTMENTS WITH INDIVIDUALS BELONGING TO DIFFERENT SPECIES

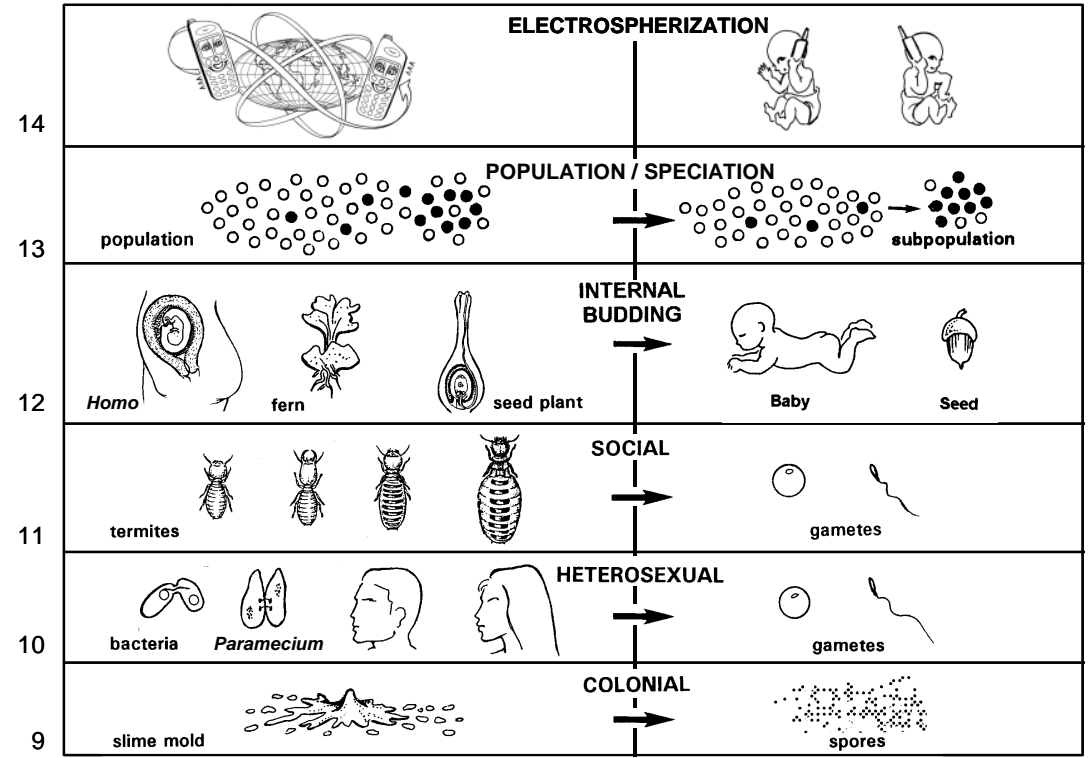

COMPARTMENTS WITH INDIVIDUALS OF THE SAME SPECIES 


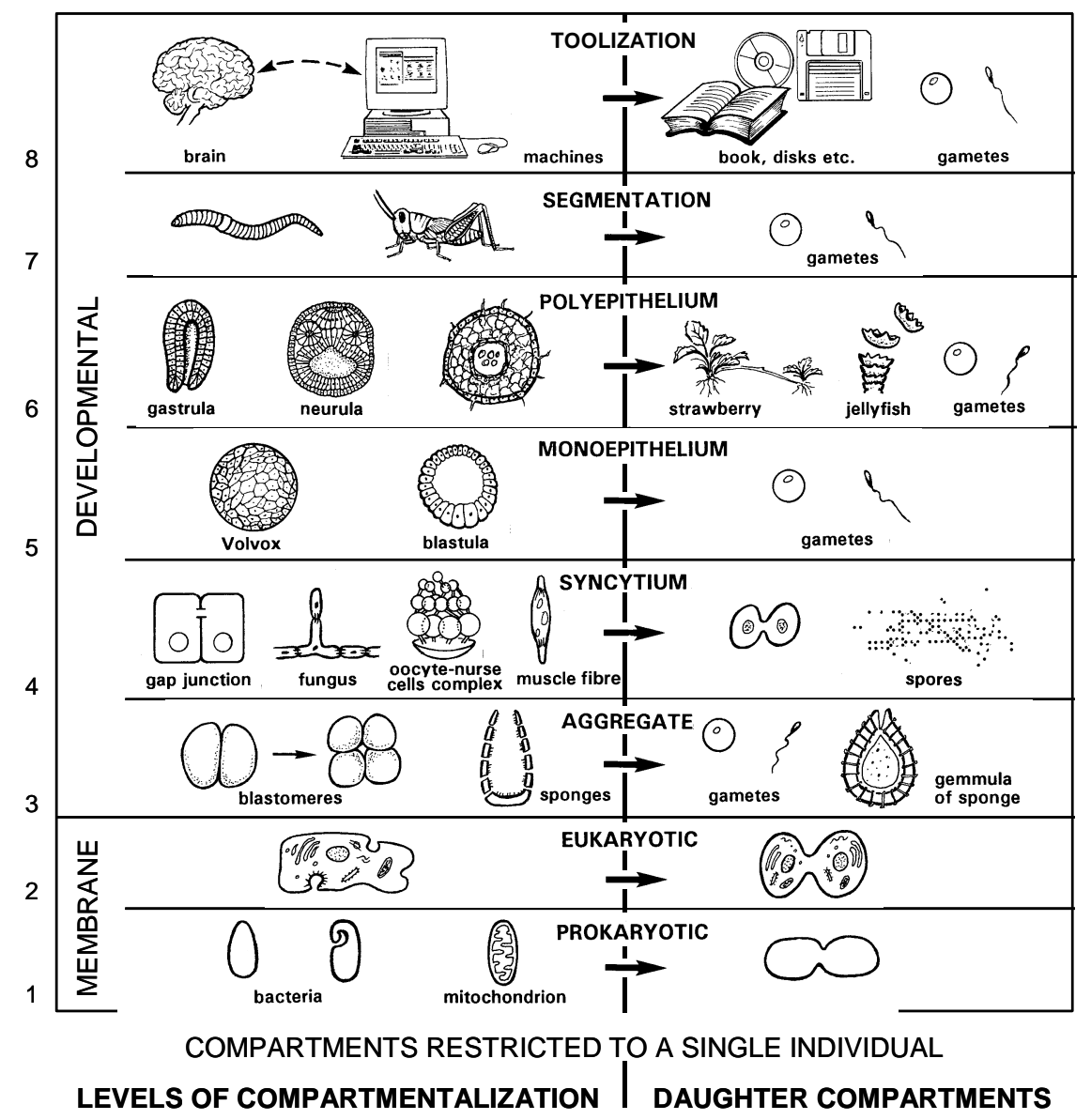

Figure 2. Successive levels of compartmentalization (left side) and means for generating daughter compartments (right side). For explanation, see text or De Loof (2002). Different levels of compartmentalization are possible within one and the same organism (2-8), within one and the same species (9-14, page 254) and within polyspecies compartments (15-16, page 253). The system as depicted here in two dimensions is not linear in time.

Figure 2 lists the key elements of this classification system to provide a glimpse of the huge number of different languages/signaling pathways/problemsolving strategies that are incessantly used in nature. The system comprises three major categories, each with subdivisions. For more details about the successive 
levels of compartmentalization and their specific problem-solving see De Loof (2002).

1. The first category (page 254) comprises compartments that can occur within the same individual: the bacterium and the cell organelle in a eukaryotic cell, the eukaryotic cell itself, the aggregate, the syncytium, the mono-epithelium, the poly-epithelium, the segmented animal, and animals with their tools (the mechanized compartment).

2. The second category (page 253) comprises compartments consisting of more than one individual, all belonging to the same species: the colony, the (heterosexual or homosexual) partner(s) entity, the organism-withinorganism (by internal budding) compartments, the population/species compartment, and the electrosphere compartment (= Homo with his electrical machines for communication).

3. The third category (page 253) lists compartments consisting of more than one individual belonging to different species: different types of complex multispecies communities and ecosystems such as host-parasite associations, food chains, and the highest possible level, the planetary or Gaiacompartmental level, encompassing the whole biosphere.

The right side of each compartment in Figure 2 depicts the major ways of reproduction: asexual, sexual, learning, etc. In contrast to the high variability in structure of the successive compartments, the methods of reproduction are less variable. They are extremely well conserved in evolution. In some systems, several reproductive mechanisms can be concurrently operational. Learning is only depicted here in level 8 but it is a universal mechanism as illustrated by the fact that bacteria, roundworms (Beets et al. 2012), insects, etc. also learn. Because of the causal link between communication and problem-solving, any Extended Evolutionary Synthesis (EES) should be able to explain the compartmental organization of living matter as depicted here in Figure 2.

With respect to the "unit of selection", a topic dealt with in numerous papers (e.g. Istvan 2013), "the gene" has often been advanced as being the primordial candidate (e.g. Dawkins 1982). Yet, Sterelny et al. (1996) rightly warned that singling out genes as the units of selection is too simplistic. In principle, not only the gene, or the gamete, but the organism, family group, population and sex (Solbrig and Solbrig 1979) could be the unit of selection (De Loof 2002).

\section{Feedback, conversation, no retrograde evolution}

Communication activity is a not a circular process as the term "feedback" might suggest at first sight. It is spiral-like (Figure 3). When a receiver responds 
to an incoming message by returning a reply message to the original sender, that sender will interpret the message and may deliver a new message, often different from the first message. The receiver cannot return the same message to the original sender, thereby restoring the physiological situation from before that message had been sent. This implies that communication unfolds unidirectionally: always forward. Retrograde communication activity is not possible. Consequently, retrograde cultural evolution is also impossible. In contrast, when a simple mutation mutates back to its original situation, retrograde organic evolution "the hardware way" (page 257) should theoretically be possible.

\section{Bifurcation points, the "software counterparts" of mutations}

In organic evolution, mutations of all sorts as well as epigenetic changes (in particular DNA methylation and histone modification) are the main sources of

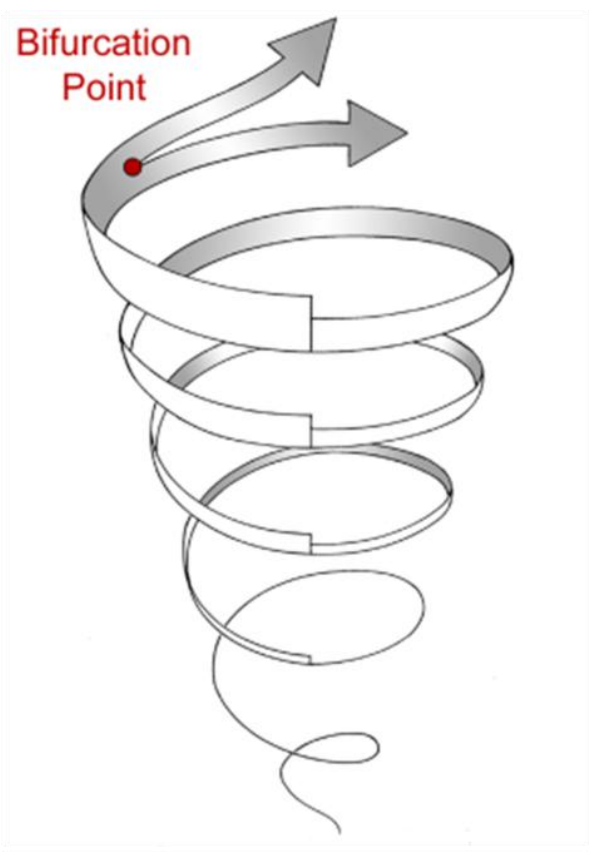

Figure 3. Feedback is not a circular but a spiral-like unidirectional process. At bifurcation points (BP), more than one answer to an incoming message is possible. Here, a choice has to be made. variability. The possibility exists that this epigenetic mechanism is at the basis of inheritance of acquired properties (e.g. by transfer of genes that cannot be functional). Bifurcations points are situations where, in a feedback system, more than one answer to an incoming message is possible (Figure 3). At bifurcation points, a choice has to be made. The more complex a communication system is, the more bifurcation points are possible. In my opinion they represent the biological basis for the existence of "free will" in the case that a decision has to be made consciously. Some scientists may disagree. The possibilities for adaptation made possible by "free will" are evidently much greater in free-living organisms than in sessile ones. The absence of a basis for free will in the genetic approach of NeoDarwinism is a major objection advanced by opponents of the strictly genetic theory of organic evolution (Pennock 2003, Zlotin and Zusman 2005). 


\section{Energy: endogenously generated bioelectricity}

Life, communication and problem-solving activities are not possible without self-generated bioelectricity carried by inorganic ions, generated by the concerted activity of ion channels and ATP-driven ion pumps that reside in the plasma membrane and some internal membranes. The principles of bioelectricity are well understood, in particular those operating in the nervous system, the seat of the cognitive memory in organisms with a brain. The central dogma (Crick 1970) only partially directs bioelectric phenomena. One should be aware of the fact that the electrical dimension of cells, in particular the voltage gradient over the plasma membrane, does not integrally arise de novo at each new generation. Indeed, during cell division (fission and the cytokinesis that generally follows mitosis and meiosis) the parent cell shares part of its functioning membrane system with the daughter cell. This sharing has been uninterrupted since the LUCA. After cell division, the central dogma will direct the synthesis of the various proteins needed for keeping the electric system going. Thus, the electrical dimension of cells is partially shared with another cell and partially inherited.

Another property of cellular electricity is the ability of many cell types, if not all, to drive an electric (ionic) current through themselves, at least during some stages of their life cycles. This has been described as "The cell as a miniature electrophoresis chamber" concept (De Loof 1986). This transcellular current results from the fact that ion pumps and channels are usually distributed asymmetrically over the plasma membrane. The full physiological significance of such transcellular currents, besides contributing to polarity, is not yet fully understood (Levin 2012). But it enables nerve cells to make action potentials, muscle cells to contract, many other cells to communicate, e.g. via electrical (gap) junctions; a cell without a membrane potential is either dying or a dead cell.

\section{Two memory systems: a hardware- and a software memory}

The body of organisms, including their brain, if present, their "hardware" in computer-era language, evidently needs a genetic memory, the nucleic acids, and the proteins it codes for, for executing all its functions. The cognitive memory system also needs proteins (e.g. Rosenegger et al. 2008, 2010; Braun and Lukowiak 2011), but that does not mean that the central dogma explains in full its functioning. There is no cognitive memory without a bioelectrical input. I have outlined elsewhere (De Loof 2002) why I think that the plasma membranecyto-nucleoskeletal complex (in particular actin-like molecules), in concert with bioelectric events, is at the heart of storing and retrieving cognitive information. To date, despite all efforts in neurobiological research, we have to humbly admit that we are hardly less ignorant about the biochemical and biophysical principles of the cognitive memory than Darwin was about the basics of genetics. Why not follow Darwin's example? He rightly valued the importance of genetic 
variability for evolution. To date, we should do the same for the cognitivememory based variation. The fact that bacteria have cognitive and computational capabilities (Shapiro 2007) suggests that the principles of a software/cognitive memory, whatever their nature, are probably as ancient as life itself.

\section{Pre-installed "software programs"}

To decode a non-genetic message, such as a spoken sentence in our daily life, a decoding program(s) (mathematicians might use the term "algorithm") had to be installed ahead of the decoding activity, and stored somewhere in the organism, in the specialized cells of our brain. It forms the basis for the "automaton aspect" of life. The more decoding programs are stored in the cognitive memory and the more efficient they are, the greater the chances for successful problem-solving "the software way". Conscious problem-solving is the exception; automated problem-solving is the general rule. This is apparent from reflex behavior, e.g. when nearing to a heat source too closely.

\section{The continuation of information and communication in the course of time}

The classical definition of reproduction falls short in evolutionary theory

In biology, reproduction means the production of a progeny "the hardware way", yielding "children". At the cellular level, the mechanics of asexual and sexual reproduction, the role of mutations and the different mechanisms of generating genetic variability in a population as well as the importance of differential reproduction of different phenotypes and its effect on fitness (Solbrig and Solbrig 1979) are very well documented. However, the existence of two memory systems, namely a genetic and a cognitive one, implies that there is a second possible means of reproduction, namely the one involving the cognitive memory, where relevant.

Sender-receiver reproduction: a double continuum with "physical children" and "pupils"

The genes of an individual are continued in its children, who in their turn pass them on. This is the genetic continuum. The continuation of information through the cognitive memory system is achieved by teaching and learning as well by imitation (Godfrey-Smith 2012) yielding "pupils". There is no need for a genetic link between teacher and pupil. This second continuum operates to some extent independently from the genetic continuum. This is a typical feature of Lamarckian evolution (Solbrig and Solbrig 1979). Both teachers and students are usually amazed (and amused) upon being challenged with the idea that teaching to children/students is a special form of "having sex", even very often group sex. Teaching-learning is reproduction the software way. The biochemical basis of the functioning of the cognitive memory is far from understood, but that 
is not an obstacle for taking its role into consideration for better understanding evolutionary theory.

\section{The significance of communication for evolution}

A reminder: from Natural Selection to the Modern Synthesis

For non-specialists in evolutionary theory, it may not be superfluous to mention that the meaning of some basic vocabulary in evolution has changed over time. In The Origin of Species by Means of Natural Selection, Darwin (1859) defined natural selection as follows: "This preservation of favorable variation and rejection of injurious variations, I call Natural Selection". With respect to "survival of the fitter", according to Solbrig and Solbrig (1979), "the fitter" meant for Darwin the one with most surviving progeny. The Solbrigs advanced the dilemma that the fittest can be a comparatively weak individual. That is why many physiologists have replaced "the fittest" by "the best adapted". With respect to that other iconic saying "struggle for life", Herbert Spencer (1820-1903) popularized the idea of "struggle" in his concept of social evolution. According to Solbrig and Solbrig (1979), the equation of evolution with struggle is a misconception. If it is, an alternative is needed. Later on, as insight into the principles of genetics deepened, Darwin's definitions became more and more reduced to a strictly genetic interpretation. According to Kauffman (1993), the essence of the Modern Synthesis became "The NeoDarwinian synthesis, the centrepiece of which is the idea that natural selection, acting upon individual variations within a population to substitute one allele $(=\mathrm{a}$ variant of a gene at the same locus) for another, is the major force driving adaptive evolutionary change". In fact, this view says that only genes matter for evolution and hence, non-genetic parameters causal to (cultural) evolution are rather irrelevant. This view cannot possibly be correct. Yet, as stated before, it is the only possible view if one assumes that there is only one type of memory and one central dogma.

\section{A modernized definition of natural selection}

A subtle adaptation of Darwin's original definition into: "This preservation of features enabling adequate over-all problem-solving and rejection of inferior ones, this I call Natural Selection", paves the way for the communication-based approach of evolution as outlined in this paper.

The overlooked causal relationship between communication and problem solving

Richard Dawkins (1976) attributed to the gene some "personality" by adding the adjective "selfish". For teaching purposes and for stimulating the interest of the public for genetics and evolution, this metaphorical adjective was a very successful strategy. Yet, it is clear that genes are neither selfish nor altruistic (neither was it meant that way by Dawkins); genes are neither black 
nor white, neither bioluminescent or not bioluminescent, etc. A gene is nothing more than a recipe on a particular page in the cell's cookbook for preparing a wide variety of protein dishes. That recipe only gets a meaning if it is first read and next used for "cooking" that particular protein meal. It is the protein that matters, not by itself, but only when embedded in the context of the whole cellular activity. A key activity of all cells is communication.

Few people will spontaneously link communication activity to problemsolving activity. Yet, if one analyzes the functioning of a communication system, one reaches the unexpected and counterintuitive (or overlooked) conclusion that each act of communication (from the production of the message in the sender to the response in the receiver) is a problem-solving act. This follows from the fact that any message, whatever its nature, is coded. Hence, any receiver invariably faces the problem of how to extract the information present in an incoming message, and how to respond to it. In my opinion, the equation,

\section{communication act $=$ problem-solving act}

represents the very essence of what evolution is all about, making meaning out of the ever-increasing diversity of signs/symbols.

The confrontation with this equation may act as an eye opener. Indeed, in daily life, we do not experience our conversations as a problem-solving activity. We understand our mother tongue, without making a special effort, because as a child our parents and other people installed in our brain, by teaching, the decoding programs for the sounds they produce and the signs and symbols they use.

\section{Adaptation, survival of the best problem-solvers}

The reason why problem solving is so crucial for evolution resides in its causal link with adaptation. The gradients in temperature, solute concentrations, etc. as well as predators and parasites present in the environment are subject to change. Hence, organisms have to solve the problems resulting from the changes; otherwise, they risk death. They have to adjust their own internal gradients continuously with the environmental ones. This involves handling of information, thus communication. Neurosensory ecology and physiology are the most relevant research fields in this context (Lukowiak and Weeks 2008). They deal with aspects of immediate problem solving in which there is no role for mutations. Gene-centered adaptation is evidently more important for long-term adaption (Cronin 2005).

Cultural evolution concerns pupils and problem-solving the software way

Many aspects of cultural evolution, as well as the emphasis given to human cultural evolution, are outlined in The Stanford Encyclopedia of Philosophy 
(2007). Mesoudi et al. (2004, 2006) stated that human cultural evolution clearly exhibits key Darwinian evolutionary properties. Umberto Eco (cited in Caesar 1999) proposed that every cultural phenomenon can be studied as communication, but this insight neither became a leitmotif among students of cultural evolution nor was it picked up by organic evolutionists.

Danchin et al. (2011) define culture as the part of phenotypic variability that results from information transmitted across generations through social learning. I would omit "across generations" because of major changes, for example, our digital-electronic information revolution happened in one generation. In my opinion, it is acceptable to define cultural evolution simply as evolution thesoftware-way making use of the problem-solving possibilities of the cognitive memory. Bacteria (Shapiro 2007), roundworms (Beets et al. 2012), insects, and many other invertebrate and vertebrate species can learn, suggesting that evolution-the-software-way is both ancient and widespread, at least in freeliving organisms. Homo sapiens is the best example of a species that no longer evolves rapidly through mutations, but that evolves very fast especially by using the possibilities of the cognitive memory. Mutations continue to play some role, e.g. in the resistance to pathogens. Sessile species like plants probably only evolve the hardware-way. Yet, given the principle of common descent, one should not a priori exclude that plants have a rudimentary memory system. The field of "plant neurobiology continues to expand. In nature, all sorts of combinations of both types of problem solving as causal to adaptation and speciation can occur in free-living species.

\section{Language variants (dialects) promote reproductive isolation and speciation}

Like changes in key-lock systems of copulation organs promote reproductive isolation the hardware way (Eberhard 1985.), so do dialects the software way, according to the principle "like attracts like" (although sometimes unlikes attract). This is overtly visible in multi-ethnic human populations, in particular in our cities and university campuses. The phenomenon is not restricted to humans. Its power for speciation has been illustrated in a remarkable paper by Grant and Grant (2009) that documents the coming into existence of a new Darwin finch species. The authors reported that in 1981 an immigrant medium ground finch, Geospiza fortis Gould, 1837, arrived on the Galapagos island called Daphne Major. Among other characteristics, it sang an unusual song. In the fourth generation after a severe drought, the lineage was reduced to a sister and brother, who bred with each other. From then on this lineage, which had inherited an unusual song, morphology and a uniquely homozygous marker allele, was reproductively isolated, because their own descendants bred with each other and with no other member of the resident $G$. fortis population. The authors stressed the importance of the culturally transmitted song component. It illustrates the well known fact that cultural evolution is faster than organic evolution (Perreault 2012). 


\section{How does "Life" evolve? Mega-evolution}

It is self-evident that an all-round theory of evolution [the long-sought New Synthesis or Extended Evolutionary Synthesis (EES)] of biological systems should describe the principles of evolution of "life". To be sure that the proposed principles are valid, life should be plausibly and unambiguously defined first. I disagree with those who claim that one does not have to know what life is, to understand biology, in particular its interrelationships. Contrary to what most specialists in both the classical biological sciences and in the humanities think, such a definition can be logically and relatively simply deduced, as outlined in detail elsewhere (De Loof 2002, De Loof and Vanden Broeck 1996). It suffices to switch from comparing the properties of the false opposites, living matter versus non-living or inanimate matter, to the true opposite situations still alive versus no longer alive or dead to unmask the very nature of life. That difference turns out to be communication at the highest level of compartmental organization. The deduced definitions read:

Death ensues when a given communicating compartment irreversibly (to avoid regeneration) loses its ability to communicate at its highest level of compartmentalization (Figure 2 for possible successive levels). This definition is compatible with what has been called "the duality of death" (De Loof 2002). An example of such a situation is a brain-dead coma patient in whom the brain (highest level of communication) no longer functions, but in whom several organs (lower level) continue to function for some time.

Life sounds like a noun but it is an activity, thus a verb. Life (L) is nothing other than the total sum $(\Sigma)$ of all acts of communication (C) executed at any given moment $(\mathrm{t})$ by a given sender-receiver compartment $(\mathrm{S})$, from its lowest level of compartmental organization (cell organelle: $\mathrm{n}=1)$ to its highest one $(\mathrm{n}=$ j) (e.g. the brain in an animal, the mutual communication in a population, etc.).

The symbolic notation of life $(\mathrm{L})$ in its simplest form reads:

$$
\text { Life }=\text { total } \operatorname{sum}\left(\sum\right) \text { of communication acts }(\mathrm{C}) \text { or: } \mathrm{L}=\sum \mathrm{C}
$$

Because "life" is invariably linked to a compartment level (e.g. cell, organism, population, etc.) a more accurate notation reads:

$$
\mathrm{L}(\mathrm{S}, \mathrm{t})=\underset{\substack{\text { compartmental level } \mathrm{j} \\ \text { compartmental level } 1}}{\mathrm{C}(\mathrm{S}, \mathrm{t}}
$$

$\mathrm{S}=\mathrm{a}$ given communicating compartment; $\mathrm{t}=$ time; compartment level 1 represents the cell organelle level, level $\mathrm{j}$ represents the highest level of 
communicational organization in complex, multicellular and multi-individual compartments (see section entitled, "How to bring order in the multitude of different communicating compartments?"located on page 252).

$$
\mathrm{L}(\mathrm{S}, \mathrm{t})=\sum_{1}^{\mathrm{j}} \mathrm{C}(\mathrm{S}, \mathrm{t})>0
$$

This definition meets all necessary conditions a good definition of life should meet according to Schetjer and Agassi (1994), in particular that it should not reduce life to merely physics and chemistry, and that there should be room for an immaterial dimension. In computer-era wording: life is the roof on a temple supported by four pillars: hardware, software, energy (in particular selfgenerated electricity) and motivation $(=$ the universal drive for reaching equilibrium, De Loof 2002). This four-pillar system modernizes the PICERAS system of Koshland (2002) in which reproduction is the roof on the seven-pillar temple, and in which, according to Koshland, who at the time was serving as Editor-in-Chief of the prestigious scientific journal, Science, "Life cannot be defined." PICERAS stands for Program, Improvisation, Compartmentalization, Energy, Regeneration, Adaptability, and Seclusion. In Figure 4 (page 264), the major differences between the classical- and the communication-based approaches of evolution are schematically depicted.

The symbolic notation for evolution (Ev) of life, or Mega-Evolution, in its simplest form reads:

$$
\mathrm{Ev}(\mathrm{L})=\Delta \sum \mathrm{C}(\mathrm{T} 2-\mathrm{T} 1),
$$

where $\mathrm{T} 1$ and $\mathrm{T} 2$ being points at the time scale of evolution.

To describe the evolution of life, the term mega-evolution has been coined before (De Loof 2002).

\section{Summary and Final Remarks}

Before the first cell became operational, there must already have been a selection of biochemical processes. It was only when their activity became sufficiently coordinated to change the physiotype of this primitive entity that "problem solving" began. For example, proton-ATPases were probably present long before changes in $\mathrm{pH}$ began to function as a signaling mechanism for changing the phyiotype of that primitive cell. Hence, my view is that "life" started when the very first cell on earth executed its first act of communication/problem-solving (Figure 5). 


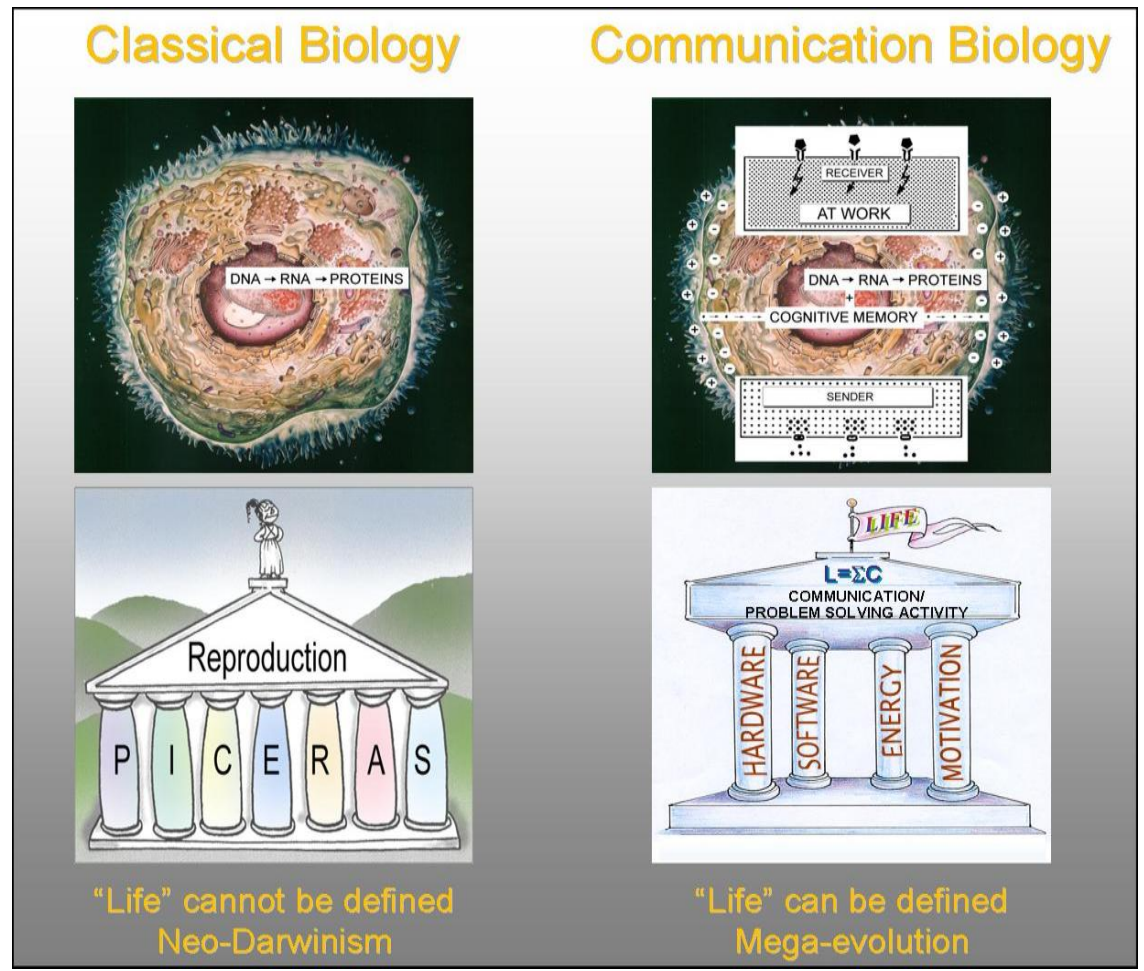

Figure 4. Comparison of the classical Neo-Darwinian approach of evolution (left side) with the communication-based approach (right side). Neo-Darwinism emphasises the possibilities for evolution of (changes in) the genetic memory (DNA) and the central dogma. In this approach, the cell (here represented by an idealized animal cell) is the basic building block of all living matter. The existence of a separate cognitive memory system, different from the genetic memory, is not considered. The drawing of the temple of PICERAS (modified after Koshland 2002) illustrates the key features of living matter as well the inability of defining "life" in this approach. PICERAS stands for Program, Improvisation, Compartmentalization, Energy, Regeneration, Adaptability and Seclusion (= specificity of enzymes). Neo-Darwinism deals with the evolution of life as a single hardware continuum. In the communication/problem-solving approach, the communicating compartment is the basic building block of all living matter. Not only DNA and the central dogma, but the electric dimension of cells [plasma membrane potential (+ and - symbols), transcellular ionic currents De Loof 1986], is also taken into account because of its crucial importance for the functioning of the cognitive memory and problem-solving the software way. The counterpart of Koshland's temple is, using computer-era vocabulary, a structure with four pillars that enables the difference making activities of living matter as compared to those of inanimate matter, namely communication- and problem-solving activity. In this approach, "life" can be defined as $\mathrm{L}=\sum \mathrm{C}$ (for explanation see text). Mega-evolution deals with the evolution of life as a hardware-software double continuum. 
Hence, rather than how do new species come into existence (speciation, Darwin 1859; Gould, 2002), a major issue in evolutionary theory should be how did the very first cell (originally named Progenote, but better named Progenate) as primordial sender-receiver compartment, evolve into the current biosphere with its millions of species and myriads of communicating compartments? Do they all differ from each other and are they interconnected, one way or another, by all sorts of languages/signalling pathways and problem-solving strategies? Or, how do genes and languages co-evolve?

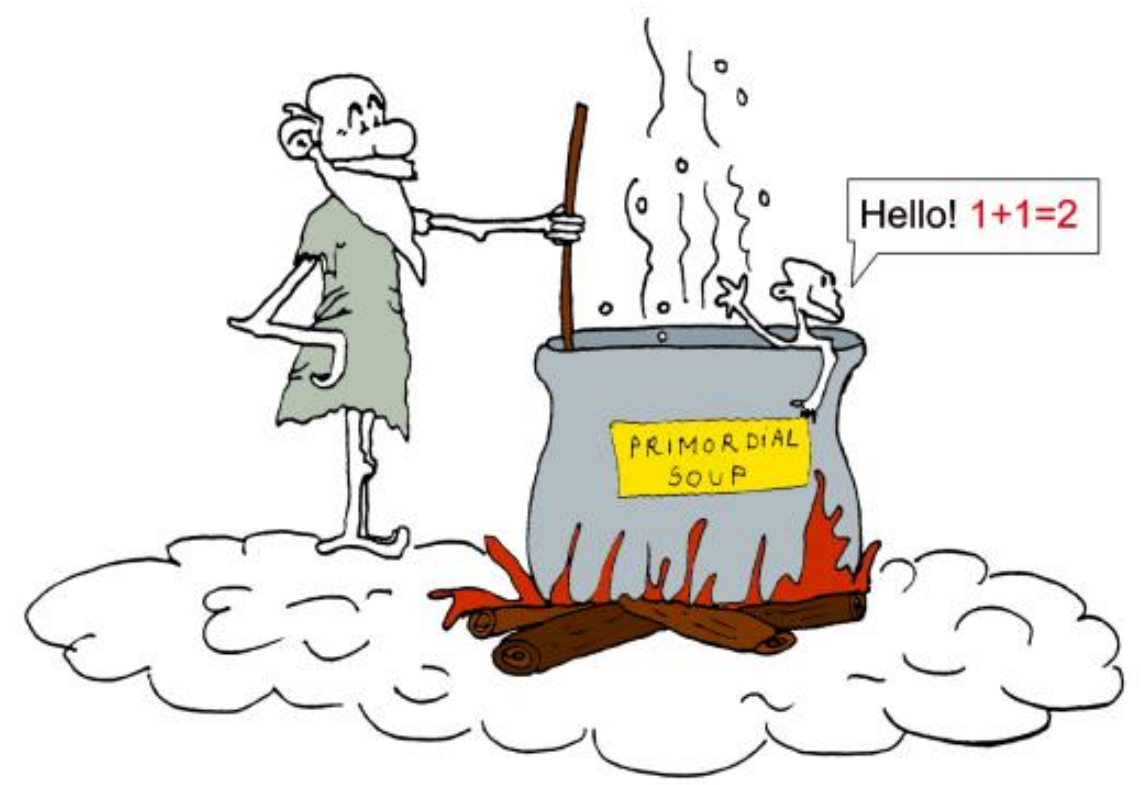

Figure 5. The very origin of life's mega-evolution. This is a cartoon for teaching purposes to draw the attention to the fact that "life" came into being at the very moment that a compartment started to communicate, thereby solving a problem. This is thought to have happened some 3.6 billion years ago. This cartoon is not intended to imply a "designer" or purposeful evolution. The primate-like entity in the cauldron represents any living organism.

The Modern Synthesis (Neo-Darwinism), with its almost exclusive emphasis on genetics (Gould 2002), describes well the mutation-driven evolution of the hardware aspect of living matter. Yet although splendid, it is an incomplete approach as illustrated by the still ongoing search for an Extended Evolutionary Synthesis (Laland et al. 2014). Indeed, until recently, the Modern Synthesis strongly undervalued the role of physiological function in influencing genetic inheritance (Noble 2013) as well as the fact that some acquired characteristics can be inherited. In particular, it did not (sufficiently) take into account all "language-based" aspects of cultural evolution (this paper). As a 
result, Neo-Darwinism does not offer an adequate platform for seamlessly unifying organic and cultural evolution. To become an all-round (or "all inclusive", Danchin and Pocheville 2014) theory of evolution, thus a "Full Synthesis", Neo-Darwinism needs to better meet physiology (De Loof 2002, Noble 2013, Danchin and Pocheville 2014), and above all it needs a "software/brain upgrade". Such an upgrade can be provided by replacing "the cell" by "the sender-receiver- or communicating compartment" as the universal unit of structure, function and selection of all living matter. By doing so, "the cell" is the smallest such unit. At first sight, such a switch may look far from radical. Yet, without invoking any unknown principle, it introduces a much more integrative way of thinking that may result in a novel communicationbased evolutionary paradigm, capable of making organic and cultural evolution the two faces of the very same coin. Its essentials are:

1. The problem-solving communicating compartment serves as the universal building block of all living matter. It harbors an "intelligent dimension" because it enables problem solving. It also enables the formation of many types of complex levels of compartmental organization as well as their interactions. It enables and facilitates social life. Genes and languages are united in the same concept.

2. In modern wording, the adapted definition of Darwin's Natural Selection can read: "This preservation of features enabling adequate over-all problemsolving and rejection of inferior ones, this I call Natural Selection".

3. Struggle for life becomes: The best problem-solvers have better chances for adaptation.

4. In survival of the fitter, not only "physical children" but, where relevant, "pupils", or intellectual progeny, also count.

5. Not only mutations, but anything that changes the existing genetic and/or cognitive signal transduction pathways with alterations in problem-solving activity as a result, can, in principle, contribute to evolutionary change.

6. Organic evolution is centred on the genetic memory, the central dogma and problem-solving the hardware way. It is Darwinian in nature. Cultural evolution is centred on the cognitive memory, the use of languages of all sorts and problem-solving the software way. It is mainly Lamarckian in nature. The cognitive memory, in itself a complex structure, must have been in place before the first act of communication was executed. 
7. Because "life" can be plausibly defined starting from the principles of communication, its evolution can be addressed as well. Mega-evolution (De Loof 2002) is the umbrella above micro-, macro-, and cultural evolution.

Paraphrasing Theodosius Dobzhanski (1973), my final message, as a (retired) teacher, to students is: When studying biology, always keep in mind that "Nothing in Biology and Evolutionary theory makes sense except in the light of communication/problem-solving activity". Extracting information from all sorts of messages as well as doing something with that immaterial information represents the very essence of that remarkable phenomenon that we call "life".

\section{Acknowledgements}

Thanks to the numerous students who served as critical audience during the development of the double continuum-approach of "life" and its evolution, to Julie Puttemans, Katrien Becuwe and Marijke Christiaens for the figures., and to Dr. Elisabth Marchal for her help with the final layout; My sincere thanks to the anonymous reviewers for their most helpful comments.

\section{Literature Cited}

Azami, S., A. Wagatsuma, H. Sadamoto, D. Hatakeyama, T. Usami, M. Fujie, R. Koyanagi, K. Azumi, Y. Fujito, K. Lukowiak, and E. Ito. 2006. Altered gene activity correlated with longterm memory formation of conditioned taste aversion in Lymnea. Journal of Neuroscience Research 84:1610-1620. http://dx.doi.org/10.1002/jnr.21045

Baronchelli, A., N. Chater, R. Pastor-Satorras, and M. H. Christiansen. 2012. The biological origin of linguistic diversity. PLoS One 7(10):e48029. http://dx.doi.org/10.1371/journal.pone.0048029

Beets, I., T. Janssen, E. Meelkop, L. Temmerman, N. Suetens, S. Rademakers, G. Jansen, and L. Schoofs. 2012. Vasopressin/oxytocin-related signaling regulates gustatory associative learning in C. elegans. Science 338:543-545. http://dx.doi.org/10.1126/science.1226860

Braun, M. H., and K. Lukowiak. 2011. Intermediate and long-term memory are different at the neuronal level in Lymnea stagnalis (L.). Neurobiology of Learning and Memory 96:403-416. http://dx.doi.org/10.1016/j.nlm.2011.06.016

Caesar, M. 1999. Umberto Eco: Philosophy, Semiotics and the Work of Fiction. Wiley-Blackwell. Hoboken, New Jersey, USA. 208 pp.

Chandler, D. 2002. Semiotics: the basics. Second Edition. Routledge. London, England, UK. 328 pp. http://dx.doi.org/10.4324/9780203166277

Crick, F. 1970. Central dogma of molecular biology. Nature 227:561-563. http://dx.doi.org/10.1038/227561a0

Cronin, H. 2005. Adaptation: a critique of some current evolutionary thought. Quarterly Review of Biology 80:19-26. http://dx.doi.org/10.1086/431021

Danchin, E., A. Charmantier, F. A. Champagne, A. Mesoudi, B. Pujol, and S. Blanchet. 2011. Beyond DNA: integrating inclusive inheritance into an extended theory of evolution. Nature Reviews Genetics 12:475-486. http://dx.doi.org/10.1038/nrg3028

Danchin, E. and A. Pocheville. 2014. Inheritance is where physiology meets evolution. Journal of Physiology 532 (Pt 11):2307-2317. http://dx.doi.org/10.1113/jphysiol.2014.272096

Danchin, E. and R. H. Wagner. 2010. Inclusive heritability combining genetic and nongenetic information to study animal culture. Oikos 119:210-218. http://dx.doi.org/10.1111/j.1600$\underline{0706.2009 .17640 . \mathrm{x}}$

Darwin, C. 1859. On the origin of species by means of natural selection, or the preservation of favored races in the struggle for life. Murray. London, England, UK. 502 pp.

Dawkins, R. 1976. The selfish gene. Oxford University Press. Oxford, England, UK. 224 pp. 
Dawkins, R. 1982. The extended phenotype. The gene as the unit of selection. Oxford University Press, Oxford, England, UK. 307 pp.

Dawkins, R. 1989. The selfish gene. Second Edition. Oxford University Press. Oxford, England, UK. $352 \mathrm{pp}$.

Day, T. and R. Bonduriansky. 2011. A unified approach to the evolutionary consequences of genetic and nongenetic inheritance. American Naturalist 178: E18-36. http://dx.doi.org/10.1086/660911

De Loof, A. 1986. The electrical dimension of cells: the cell as a miniature electrophoresis chamber. International Review of Cytology 104:251-352. http://dx.doi.org/10.1016/S0074$\underline{7696(08) 61927-0}$

De Loof, A. 2002. Communication, Life, Mega-Evolution. Decrypting Life's Nature. Leuven University Press. Leuven, Belgium. 346 pp.

De Loof, A. and J. Vanden Broeck. 1996. Communication: the key to defining "life", "death" and the force driving evolution. "Organic chemistry-based-" versus "artificial" life. Belgian Journal of Zoology 125:5-28.

Dobzhansky, T. 1973. Nothing in biology makes sense except in the light of evolution. American Biology Teacher 35:125-129. http://dx.doi.org/10.2307/4444260

Eberhard, W. G. 1985. Sexual Selection and Animal Genitalia. Harvard University Press, Cambridge, Massachusetts, USA. 244 pp. http://dx.doi.org/10.4159/harvard.9780674330702

Eco, U. 1978. A Theory of Semiotics. Indiana University Press. Bloomington, Indiana, USA. 368 pp.

Godfrey-Smith, P. 2012. Darwinism and cultural change. Philosophical Transactions of the Royal Society 367:2160-2170. http://dx.doi.org/10.1098/rstb.2012.0118

Gould, S. J. 2002. The Structure of Evolutionary Theory. The Belknap Press of Harvard University Press. Cambridge, Massachusetts, USA. 1,464 pp.

Grant, P. R. and B. R. Grant. 2009. The secondary contact phase of allopatric speciation in Darwin's finches. Proceedings of the National Academy of Sciences of the Unites States of America 106:20141-20148. http://dx.doi.org/10.1073/pnas.0911761106

Huang, S. 2011. The molecular and mathematical basis of Waddington's epigenetic landscape: A framework for post-Darwinian biology? Bioessays 34:149-157. http://dx.doi.org/10.1002/bies.201100031

Istvan, M. A. Jr. 2013. Gould talking past Dawkins on the unit of selection issue. Studies in History and Philosophy of Biological and Biomedical Sciences 44:327-335. http://dx.doi.org/10.1016/j.shpsc.2013.05.020

Kauffman, S. A. 1993. The origins of order. Self-organization and selection in evolution. Oxford University Press. Oxford, England, UK. 734 pp.

Koshland, D. E., Jr. 2002. The seven pillars of life. Science 292:2215-2216. http://dx.doi.org/10.1126/science.1068489

Laland, K., T. Uller, M. Feldman, K. Sterelny, G. B. Müller, A. Moczek, E. Jablonka, J. OdlingSmee, G. A. Wray, H. E. Hoekstra, D. J. Futuyma, R. E. Lenski, T.F. Mackay, D. Schluter, and J. E. Strassmann. 2014. Does evolutionary theory need a rethink? Nature 514(7521):161-164. http://dx.doi.org/10.1038/514161a

Levin, M. 2012. Molecular bioelectricity in developmental biology: new tools and recent discoveries. Bioessays 34:205-217. http://dx.doi.org/10.1002/bies.201100136

Lukowiak, K. and J. Weeks. 2008. Neurosensory Ecology. Journal of Experimental Biology 211:1705. http://dx.doi.org/10.1242/jeb.019471

Mesoudi, A., A. Whiten, and K. N. Laland. 2004. Perspective: Is human cultural evolution Darwinian? Evidence reviewed from the perspective of the Origin of Species. Evolution 58:111.

Mesoudi, A., A. Whiten, and K. N. Laland. 2006. Towards a unified science of cultural evolution. The Behavioral and Brain 29:329-347. http://dx.doi.org/10.1017/S0140525X06009083

Moore, A. 2012. Towards the new evolutionary synthesis: Gene regulatory networks as information integrators. Bioessays 34:87. http://dx.doi.org/10.1002/bies.201290000 
Noble, D. 2013. Physiology is rocking the foundations of evolutionary biology. Experimental Physiology 98:1235-1243. http://dx.doi.org/10.1113/expphysiol.2012.071134

NOVA. 2007. Judgment Day: Intelligent Design on Trial. http://video.pbs.org/video/980040807/

Padian, K. 2007. The evolution of creationists in the United States: Where are they now, and where are they going? Comptes Rendus Biologies 332:100-109. http://dx.doi.org/10.1016/j.crvi.2008.07.004

Parvez, K., O. Stewart, S. Sangha, and K. Lukowiak. 2005. Boosting intermediate-term into longterm memory. Journal of Experimental Biology 208:1525-1538. http://dx.doi.org/10.1242/jeb.01545

Pennock, R. T. 2003. Creationism and intelligent design. Annual Review of Genomics and Human Genetics 4:143-163. http://dx.doi.org/10.1146/annurev.genom.4.070802.110400

Perreault, C. 2012. The pace of cultural evolution. PLoS One 7(9):e45150. http://dx.doi.org/10.1371/journal.pone.0045150

Reali, F. and T. L. Griffiths. 2010. Words as alleles: connecting language evolution with Bayesian learners to models of genetic drift. Proceedings of the Royal Society B 277:429-436. http://dx.doi.org/10.1098/rspb.2009.1513

Rosenegger, D., K. Parvez, and K. Lukowiak. 2008. Enhancing memory formation by altering protein phosphorylation balance. Neurobiology of Learning and Memory 90:544-552. http://dx.doi.org/10.1016/j.nlm.2008.06.005

Rosenegger, D., C. Wright, and K. Lukowiak. 2010. A quantitative proteomic analysis of long-term memory. Molecular Brain 3:9. http://dx.doi.org/10.1186/1756-6606-3-9

Schetjer, A, and J. Agassi. 2002. On the definition of life. Journal of General Philosophy of Science 25:97-106.

Shapiro, J. A. 2007. Bacteria are small but not stupid: cognition, natural genetic engineering and socio-bacteriology. Studies in History and Philosophy of Biological and Biomedical Sciences 38:807-819. http://dx.doi.org/10.1016/j.shpsc.2007.09.010

Solbrig, O. T. and D. J. Solbrig. 1979. An introduction to population biology \& evolution. AddisonWesley Publishing Company. Reading, Massachusetts, USA. 468 pp.

Sterelny, K. 2000. The "genetic program" program. A commentary on Maynard Smith on information in biology. Philosophy of Science 67:195-201. http://dx.doi.org/10.1086/392769

Sterelny, K., K. C. Smith, and M. Dickison. 1996. The extended replicator. Biology and Philosophy 11:377-304. http://dx.doi.org/10.1007/BF00128788

Stanford Encyclopedia of Philosophy. 2007. Cultural evolution http://plato.stanford.edu/entries/evolution-cultural/ 1-20.

Zlotin, B. and A. Zusman. 2005. A brain for intelligent design. A new concept for biological evolution. Idealation International Inc. Southfield, Michigan, USA. 10 pp. http://www.ideationtriz.com/Zlotin_Zusman_Natural_Brain_for_Intelligent_Design.pdf 